\title{
Shopping Anytime Anywhere
}

\author{
Kenton O'Hara ${ }^{\pi}$, and Mark Perry ${ }^{\tau}$ \\ ${ }^{\pi}$ The Appliance Studio, University Gate, Park Row, Bristol, UK. kenton@ appliancestudio.com \\ ${ }^{\tau}$ Department of IS \& Computing, Brunel University, Uxbridge, UK. mark.perry @ brunel.ac.uk
}

\begin{abstract}
When people walk around in the world, many impulses to make a transaction are generated by objects in the environment. For many reasons these transaction impulses are deferred. A study of consumer behaviour is presented focussing on why these transaction impulses are deferred. By looking at the reasons for deferral the aim is to inform the design of new user-centred mobile e-commerce devices and services that can overcome these deferral reasons.
\end{abstract}

\section{INTRODUCTION}

The physical environment is a rich source of stimulation and information for the consumer. Impulses to buy products and services are generated as we move around our environment and interact with the physical world. A key promise of emerging m-commerce devices and services over WAP (wireless application protocol) is that these impulses can be acted upon immediately, anytime and anywhere they occur. These mobile devices respect the important influence of the physical environment on shopping behaviour as well as providing the flexibility of on-line e-commerce environment. With new technological infrastructures such as, for example, Hewlett-Packard's Cooltown [2], the physical environment can be linked to Internet-based sources accessible through mobile devices. This will allow contextually relevant information to be presented to the user for more informed purchasing decisions and access to online m-commerce services for in the moment purchasing [1].

However, current mcommerce services have been subject to a barrage of adverse criticism and are not regarded as genuinely compelling [3]. Much of the development in this area remains primarily technological. Applications are often demonstrators of the technology concept rather than compelling applications in themselves. While consumer behaviour has been much studied (e.g. [4, 5]) it is usually directed towards an audience of advertisers, or those seeking a cultural critique of consumption. We have found little user understanding that can directly inform design of new m-commerce devices and services. We present a study to develop this user understanding, and to explore the notion of m-commerce as shopping anytime, anywhere. The study explores those moments when impulses are generated as we move around the environment. In particular it focuses on the reasons why they defer completing these transactions. By understanding the nature of these impulses and the reasons for deferral, new user-centred technologies and services can be developed to help overcome some of the reasons for deferral while mobile.

\section{METHOD}

Sixteen participants were chosen to represent: different age groups; gender; family status (married, single, children); educational attainment; occupation; income and social class. The mixed sample was not intended to provide detailed segmentation data but rather provided an opportunity for issues related to these different factors to be raised. Participants were told that we were interested in those instances where a stimulus in the physical environment created an impulse to make a transaction (e.g. physical consumables, services, entertainment and leisure activities that they were interested in purchasing). The participants were then given a set of disposable cameras and asked to keep a "photo diary" over the course of a week of all instances where such impulses were not fulfilled immediately but were for some reason were deferred temporarily or permanently. A follow-up interview was then conducted during which participants would elaborate on the detailed context of these events and the reasons why the impulses were deferred. The specifics of these events were also used to elicit more general information about participants' shopping and transaction behaviours.

\section{FINDINGS}

Participants took on average 36 photographs over the course of the week (range 17 to 74). Impulses were generated from a wide range of different stimuli, including the transaction objects or something similar $(50 \%)$, objects with idiosyncratic semantic relationship to transaction object (21\%), electronic media such as Internet and TV (3\%), and paper-based media such as newspapers, magazines and posters $(26 \%)$. This suggests that half of the opportunities for fulfilling deferred transactions could be supported by direct interaction between mobile devices and the transaction objects themselves - for example, by incorporating URL or barcode-scanning technology into phones and PDAs. This could also apply to interaction between mobile devices and the significant percentage of paper-based media that led to deferred transaction impulses.

The location of generated impulses was also of interest when thinking about mobile e-services. The majority of deferred impulses were generated at home (38\%). This was primarily due to provisioning goods that needed restocking as well as being the primary place for reading magazines and catalogues. Thirty percent of the deferred impulses were generated either in the shops or at shop windows. The remainder were generated while out and about walking $(25 \%)$ or in a vehicle $(9 \%)$. Approximately two thirds of deferred impulses, then, occurred while mobile where there is more difficult access to information resources. This gives an indication of the opportunity for mcommerce devices and services.

While some of these deferrals were due a lack of transaction opportunity (being away from a retail environment) there were a significant number for which there were other reasons. These were unpacked during the interviews. We present here some of the key findings that can help guide the design of context aware mobile devices to support shoppers. 


\section{Consumer behaviour is social and collaborative}

Much of the consumer behaviour was not solely an individual transaction, but rather was highly social and collaborative. One reason why people deferred fulfilling an impulse was because they needed to seek reassurance and advice about potential purchases. Several participants described instances where they showed pictures from magazines or drew pictures of objects to aid discussion and gather reassurance. Permission seeking was also an important feature of behaviour for transaction decisions based around shared financial resources or aesthetic requirements. There were also many examples of deferred transactions based around social activities, such as visits to the cinema, theatre, seeing a band, or weekend breaks with friends. They could typically not respond to these immediately by making a transaction even with access to a mobile phone, because these events involved some form of social co-ordination in terms of friends' availability on those dates and their level of interest in the event.

Facilitation and encouragement of these aspects of consumer behaviour is a fruitful space within which to explore new technologies and services. These will be based on supporting social co-ordination, capture and communication of conversational resources based for the sharing of information. In addition, collaborative filtering techniques based on the social need for advice, reassurance and adhering to social norms is an important area to consider. Consider for example, mobile services similar to Amazon.com's "people who bought $\mathrm{X}$ also bought $\mathrm{Y}$ and Z". Similarly, mobile services might build on the "email a friend" model to inform others of things such as special offers or other interesting transaction possibilities.

\section{Information seeking and analysis not in the moment}

Transactions were also deferred due to lack of information at the point of impulse generation. This is one area where context aware mobile information services are considered to be of potential value, by providing the necessary information in-the-moment, allowing the decision to be made to fulfil the transaction. One difficulty with this viewpoint is that information seeking was in many instances more than simply requesting some information 'in the moment' that would help make this decision.

Often the information required and the type of analytical processing to be done on it was more complicated than could be dealt with by the participants at the time and was deferred until they had more time and space to devote to this activity. For example, one participant saw a poster in a bank that made him think about opening a savings account. However, he wanted to get further information about this particular savings account and compare it with a range of others. This was not something that could be performed in the midst of his ongoing activities and required better visualisation of the information than would be possible on a mobile phone or PDA. He resolved this by buying a newspaper over the weekend and comparing savings rates and making detailed notes. What this suggests is that rather than presenting context specific information in the moment, m-commerce devices and services should focus on collecting references or tokens to information that can be followed up at a more convenient time, and environment, and within a more appropriate task context, using more appropriate media to support the information processing.

\section{Consumption is not a pinpoint decision process.}

Rather than thinking of consumer behaviour as transactions in the moment, it is perhaps more useful to think about consumer behaviour as transactions narratives that grow from an initial impulse seed to (perhaps) a final transaction. Many of the participants talked of mental wish-lists that they carried round with them full of desirable items that they were juggling around and considering for purchase sometime in the future. With certain key items on this mental "list", participants would enjoy boking for more information on the product. The research behaviour would go on for extended periods and was not about finding out more but rather was more of a "flirtation" with the product. The act of reading about the product, seeing images, hearing sounds related to the object were enjoyable activities in themselves and were ways of getting "close" to a product without actually fulfilling the transaction. Participants sometimes deliberately avoided in-the-moment consumption and deferred a transaction to "cool off". This allowed them to test whether the impulse was genuine or gratuitous.

Rather than simply focussing on reducing the gap between impulse and transaction, m-commerce technologies can play a role here by nurturing impulses over time - allowing them to be revisited and considered in combination with additional information about the products that could be generated or collected by the device.

\section{DISCUSSION AND CONCLUSIONS}

The study presents a user-centred approach to the design of m-commerce technologies and services. By highlighting important aspects of consumer behaviour and reasons why people currently defer transactions, we can motivate designs for technologies and services appropriate to the needs and requirements of shoppers. In particular, we would encourage the development of services that respect and support: the social and collaborative aspects of shopping; collection of information for use at an appropriate time, environment and frame of mind to interpret and judge that information; the nurturing of impulses rather than simply reducing the gap between stimulus and transaction.

\section{REFERENCES}

[1] Randall, C. and Muller, H. (2000) The Shopping Jacket: Wearable Computing for the Consumer. In Personal Technologies, 4, 241-244.

[2] Kindberg, T., Barton, J., Morgan, J., Becker, G., Caswell, D., Debaty, P., Gopal, G., Frid, M., Krishnan, V., Morris, H., Schettino, J., \& Serra. B. (2000) www.cooltown.com/papers/webpres/WebPresence.htm

[3] Pringle, D. (2000) BT's Cellnet unit falls short of It's Target for Handset Sales. http://interactive.wsj.com/articles /SB96279466884566078.htm.

[4] Miller, D. (1998) A Theory of Shopping. Cambridge: Polity Press.

[5] Jackson, S. \& Moores, S. (1995) The Politics of Domestic Consumption: Critical Readings. London: PrenticeHall. 